УДК 630:628.8:911.5/.9

\title{
ОЦЕНКА ВОССТАНОВИТЕЛЬНОЙ ДИНАМИКИ РАСТИТЕЛЬНОГО ПОКРОВА ЛЕСНЫХ ГАРЕЙ С ИСПОЛЬЗОВАНИЕМ ДАННЫХ СО СПУТНИКОВ LANDSAT
}

\author{
Токарева Ольга Сергеевна ${ }^{1}$, \\ ost@tpu.ru
}

\author{
Алшаиби Ахмед Джамал Абдулрахман², \\ ahmedalshaiby88@gmail.com \\ Пасько Ольга Анатольевна ${ }^{3}$, \\ oap@tpu.ru \\ 1 Национальный исследовательский Томский политехнический университет, \\ Россия, 634050, г. Томск, пр. Ленина, 30. \\ 2 Главное управление образования Диялы, \\ Ирак, 32001, г. Бакуба, пр. Альмухафада, 1. \\ 3 Агрофизический научно-исследовательский институт, \\ Россия, 195220, г. Санкт-Петербург, Гражданский просп., 14.
}

\begin{abstract}
Актуальность. До 400 тысяч лесных пожаров, ежегодно возникающих на Земле, ведут к попаданию в атмосфреру до четырех миллиардов тонн углерода и выгоранию до 0,5 \% площади лесов. Лесные пожары уничтожают древесные ресурсы, снижают эффективность их использования, наносят экономике гигантский урон. Оперативная и объективная информация об их последствиях востребована для решения комплекса теоретических и практических задач в области землеустройства, кадастра и мониторинга земель лесного фонда, а также для научного обоснования использования, восстановления, охраны и защиты лесов. Объект: земли лесного фонда, подвергшиеся пожарам.

Предмет: пост-пирогенная динамика растительного покрова на примере лесных гарей Томской области.

Методы: тематическое картирование территории по состоянию растительности; оценка значений NDVI (Normalize Difference Vegetation Index) и нормализованного индекса гарей NBR (Normalized Burn Ratio) по данным дистанционного зондирования Земли; анализ информации со спутников Landsat 5 (камера TM), 7 (ETM+) и 8 (OLI) с использованием геоинформационных технологий и статистической обработки полученных данных.

Результаты. Произведена оценка состояния растительного покрова гарей в сравнении с тестовым лесным участком сходного породного состава (46 \% - сосна сибирская, 36 \% - береза повислая, 11 \% - осина обыкновенная, 7 - \% сосна обыкновенная и лиственница сибирская). Степень повреждения растительного покрова изученных гарей охарактеризована как низкая. Для гарей и фонового участка рассчитаны нормализованный вегетационный индекс (NDVI) и индекс гарей (NBR). Выявлены резкие перепады их значений и аномальный ход годовой динамики для гарей. Значения NDVI для гарей и тестового участка различались на 3-56 \%, значения NBR на 20-198 \%. Различия сохранялись и спустя 17 лет после пожара. Корреляционный анализа выявил достоверную связь между значениями индексов NBR и NDVI гарей и средними значениями температуры воздуха и количества осадков в пожароопасный сезон. Она оказалась отрицательной средней и слабой силы для мая; сильной и средней для июля и слабой для августа. Осадки связаны со значениями индексов NBR и NDVI гарей со средней силой: в мае и июне отрицательно, в августе положительно. Это свидетельствует о достаточном увлажнении экотопов в начале вегетационного периода, последующем просыхании почвы, оптимальном для жизнедеятельности деревьев, и ее иссушении, предопределяющем возможность возникновения лесных пожаров. Отмечена явная территориальная изменчивость значений NDVI u NBR в границах гари.
\end{abstract}

\section{Ключевые слова:}

NDVI, лесная гарь, растительный покров, дистанционное зондирование, NBR, лесной пожар.

\section{Введение}

Ежегодно практически на всех континентах возникает от 300 тыс. до трех млн лесных пожаров, что связывают с природными явлениями (молнии) [1], ростом городов и плотности населения, изменением моделей землепользования, ухудшением социальной и экологической защиты окружающей среды, усилением хозяйственной и промысловой деятельности человека [2].

Обширные лесные пожары типичны для Евразии (Греция, Испания, Португалия, России, Франция) [3], Северной Америки (США, Канада) [2] и Австралии. В двадцати четырех странах Европы (за исключением России), крупномасштабные (>40 га) пожары ежегодно затрагивают около 300 тыс. га территории [4]; в Север- ной Америке прирост площади гари и горельников составляет $0,1 \%$ от площади лесов [5]. В Юго-Восточной Азии выгорание лесов сезонно, особенно в засушливые периоды из-за неконтролируемых лесозаготовок [6].

В России сосредоточено более четверти мировых запасов древесины (82 млрд м $\left.{ }^{3}\right)$. Более двух третей ее территории покрыто лесами [7], поэтому пожары как неуправляемое опасное природное явление [8] ведут к крупнейшим экономическим потерям страны [9], а также деградации лесных ресурсов и лесорастительных условий [10].

В России ежегодно возникает 10-34 тыс пожаров. Они уничтожают лесные массивы на территории более 18 млн га, из которых 1,2 млн га охраняются активно, а 12-36 тыс. га - особо [11]; в категорию гарей 
переходит 10-20 \% площади лесных земель, пройденных пожарами. В настоящее время накопленная площадь гарей составляет 28,4 млн га.

К наиболее пожароопасным регионам России относят Дальневосточный, Приволжский и Сибирский федеральные округа. Леса Сибири занимают около 80 \% лесопокрытой территории России (552 млн га). Ежегодно на них возникает около 30 тыс. пожаров площадью около 10 млн га. В 2010 г. отмечено более 39 тыс. лесных пожаров, в ходе которых на корню сгорело более 150 млн м $^{3}$ лесов. В Томской области ежегодно возникают 64-527 лесных пожаров на площади до 22,5 тыс. га [12], около трети которой превращается в непродуктивные территории, в т. ч. гари [13]. Происходит гибель древостоя, обезлесение и заболачивание территории, нарушение естественного лесовосстановления леса на несколько столетий и соответствующее снижение эколого-экономической ценности лесных ресурсов [14].

Ликвидация последствий пожаров требует значительных средств [15], что повышает требования к объективности, актуальности и точности измерения площадей лесов, пройденных пожарами. Существует острая потребность в оперативном выявлении площадей лесных пожаров и в оценке степени повреждения древостоев, в т. ч. удаленных и труднопроходимых территорий земель лесного фонда, а также в мониторинге сукцессии растительного покрова на нарушенных землях. Решить эти задачи позволяют современные методы дистанционного зондирования Земли и программные средства мониторинга состояния древостоя [16-18]. Многошаговые процедуры обработки разновременных спутниковых снимков в сочетании с вегетационными индексами повышают точность оценки временно-территориальной динамики растительного покрова [19]. С их помощью выявляют причины возгорания, прогнозируют распространение пожаров [20], дают количественную и качественную оценку выгоревшим лесам [21-24], анализируют и прогнозируют последствия [25], что особенно важно на территории нефтедобычи [26]. Архивы спутниковых данных за длительные промежутки времени позволяют оценивать динамику состояния растительного покрова.

Глобальное потепление климата ведет к прогнозируемому усилению пожароопасной обстановки на планете [27-29], росту грозовой активности [30] и др. Это актуализирует учет климатических и метеорологических условий возникновения лесных пожаров и развития гарей. Целью исследования является оценка постпирогенной динамики древостоя путем анализа ретроспективных данных спутниковых снимков Landsat в Томской области с учетом погодных условий.

\section{Объекты и методика}

Для анализа пост-пирогенной динамики древостоя использован тестовый участок на территории Васюганского лесничества (рис. 1). Леса, расположенные на нем, по целевому назначению являются эксплуатационными, т. е. их освоение предназначено для устойчивого и максимально эффективного получения высококачественной древесины и других лесных ресурсов с условием обеспечения полезных функций лесов. При выборе участка учтены следующие требования: большое число ежегодных пожаров; необходимое и достаточное число архивных безоблачных снимков на максимальную глубину (18 лет); возможность определения периода возникновения гарей (1998-1999 гг.). Важным моментом является территориальная близость к нему объектов нефтегазового комплекса, для которых лесные пожары крайне опасны в связи с возможностью выхода и воспламенения топлива при повреждении трубопроводов. Информация о динамике лесных пожаров, степени повреждения и восстановления растительного покрова позволяет прогнозировать вероятность хода развития событий и принимать соответствующие превентивные меры.

Пространственное разрешение использованных снимков со спутников Landsat составляет 30 м. Они загружены из архива Геологической службы США. Дополнительно использован интернет-сервис Earth Explorer.

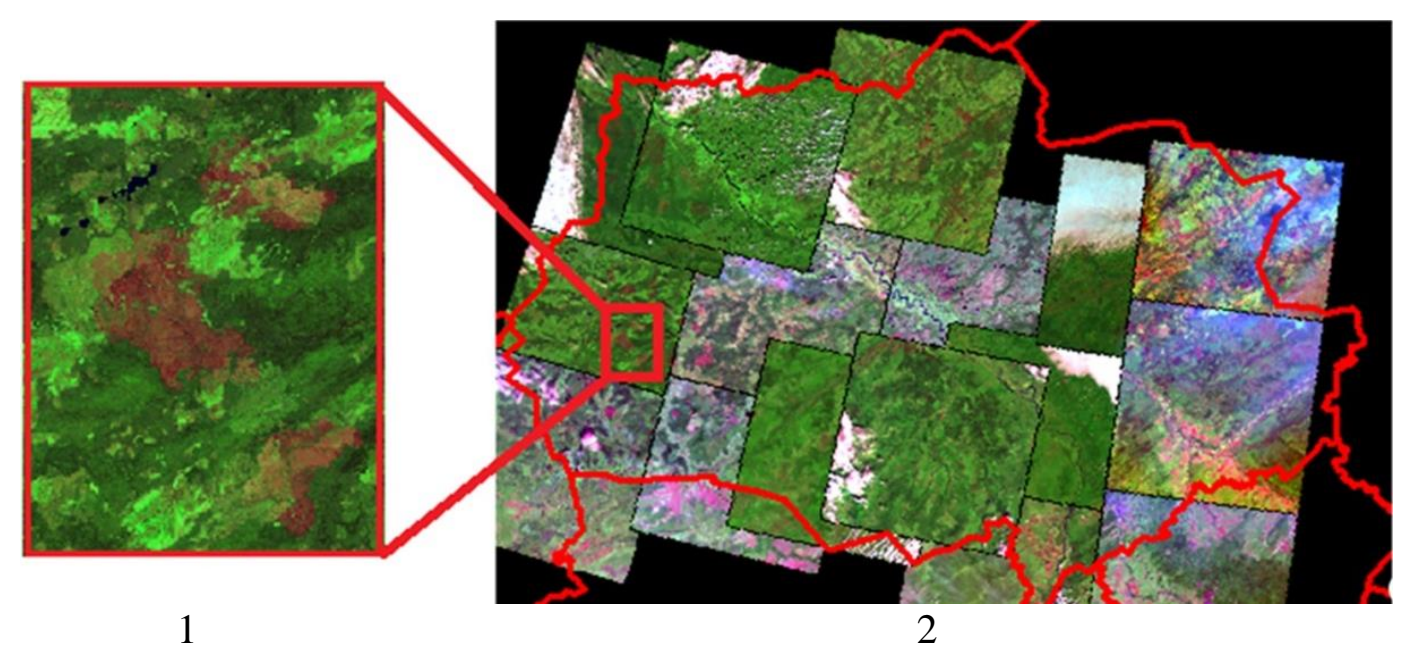

Рис. 1. Схема покрытия космоснимками территории Томской области (1) с указанием тестового участка с нанесенными полигонами (гари) в 1999 г. (2)

Fig. 1. Scheme of the coverage of the Tomsk region territory with satellite images (1) with indication of the test area with applied polygons (burnt forest area) in 1999 (2) 
Объективным интегральным показателем состояния растительности является ее отражательная способность, которая имеет ярко выраженные особенности в определенных областях электромагнитного спектра. Для таежной зоны Западной Сибири наиболее информативен показатель количества фотосинтетически активной биомассы NDVI (нормализованный относительный индекс растительности) [31], который рассчитывают по формуле (1):

$$
N D V I=\frac{\rho_{\text {nir }}-\rho_{\text {red }}}{\rho_{\text {nir }}+\rho_{\text {red }}}
$$

где $\rho_{\text {nir }}-$ значения спектральной яркости пикселей в ближней инфракрасной, $\rho_{\text {red }}-$ в красных областях электромагнитного спектра.

Путем сравнения значений NDVI по разновременным снимкам производят оценку динамики состояния растительности территорий [26].

Критерием для выявления границ лесных гарей является снижение спектральной яркости пикселей в ближней инфракрасной области спектра. Для его количественной оценки используют значения нормализованного индекса гарей NBR (Normalized Burn Ratio), рассчитываемые по формуле (2) [32]:

$$
N B R=\frac{\rho_{\text {nir }}-\rho_{\text {swir } 2}}{\rho_{\text {nir }}+\rho_{\text {swir } 2}},
$$

где $\rho_{\text {nir }}, \rho_{\text {swir2 }}-$ значения спектральной яркости пикселей в ближней и средней инфракрасных областях электромагнитного спектра соответственно.

Значения индексов NBR и NDVI в высокой степени коррелируют с данными полевых обследований гарей и горельников. Их уверенно используют в лесной службе США для практической оценки степени повреждения лесов от пожаров [3], выделения границ свежих гарей и оценки степени повреждения огнем растительного покрова разных участков (табл. 1).

Таблица 1. Соответствие степени повреждения огнем растительного покрова значениям $d N B R$

Table 1. Correspondence of the degree of fire damage to vegetation cover to the dNBR values

\begin{tabular}{|l|c|}
\hline $\begin{array}{c}\text { Степень повреждения растительного покрова } \\
\text { Degree of damage to vegetation cover }\end{array}$ & dNBR \\
\hline Отсутствует/Absent & $\begin{array}{c}\text { Меньше } 0,085 \\
\text { Less than } 0,085\end{array}$ \\
\hline Низкая/Low & $0,084-0,25$ \\
\hline Средняя/Average & $0,25-0,6207$ \\
\hline Сильная/Strong & $\begin{array}{c}\text { Больше } 0,6207 \\
\text { More than } 0,6207\end{array}$ \\
\hline
\end{tabular}

Для оценки восстановительной динамики растительности на месте лесных гарей на тестовом участке в работе использованы космоснимки со спутников Landsat 5 и Landsat 7 (камера TM и ETM+, соответственно), а также Landsat 8 (сканер OLI) [33]. Перечень снимков приведен в табл. 2. Данные, полученные в калиброванном виде, пересчитаны в коэффициенты спектральной яркости по алгоритмам, представленным в $[33,34]$.

Породный состав деревьев определен с использованием лесотаксационной карты тестового участка, далее рассчитаны площади, занятые каждой породой. Для фонового участка и каждого типа выгоревшего леса рассчитаны средние значения индексов NDVI и NBR по годам [32]; проведено сравнение постпирогенной динамики растительного покрова. Фоновый участок выбран максимально близко от территории гари. По площади он сопоставим с ней и характеризуется близким породным составом деревьев.

Таблица 2. Список снимков, покрывающих территорию тестового участка (1998-2015 г2.)

Table 2. List of images covering the test site (1998-2015)

\begin{tabular}{|c|c|c|}
\hline $\begin{array}{c}\text { Дата съемки } \\
\text { Shooting date }\end{array}$ & $\begin{array}{c}\text { Идентификаторы } \\
\text { снимков Path-Row } \\
\text { в системеWRS-2 } \\
\text { Ids of Path-Row snapshots } \\
\text { in the WRS-2 system }\end{array}$ & $\begin{array}{c}\text { Номер } \\
\text { спутника } \\
\text { Landsat } \\
\text { Landsat } \\
\text { satellite } \\
\text { number }\end{array}$ \\
\cline { 1 - 2 } $\begin{array}{c}\text { 21.05.1998,31.08.2006, } \\
\text { 17.07.2007, 20.06.2009, } \\
14.06 .2011\end{array}$ & $153-19$ & \multirow{2}{*}{5} \\
\cline { 1 - 2 } $24.06 .2008,19.06 .2010$ & $154-19$ & \multirow{2}{*}{7} \\
\cline { 1 - 2 } 03.07 .1999 & $153-19$ & \multirow{2}{*}{8} \\
\cline { 1 - 2 } 02.07 .2002 & $154-19$ & \\
\hline $25.06 .2013,29.06 .2014$, & $153-19$ & \\
\cline { 1 - 2 } 2.06 .2016 & &
\end{tabular}

Для определения влияния метеорологических факторов на динамику гарей проведен корреляционный анализ зависимости средних значений NDVI и NBR от температуры и количества осадков в пожароопасный сезон (по месяцам) по данным Гидрометеоцентра Томской области [37]. Теснота связи между показателями оценена с помощью опции «Сводная таблица» программы EXCEL.

\section{Результаты и обсуждение}

На основе анализа космического снимка дано описание гарей тестового участка в 1999 г. (рис. 1, табл. 3). Породный состав леса был на 46 \% представлен сосной сибирской, на $36 \%$ - березой повислой, на $11 \%$ осиной обыкновенной и на $7 \%$ - сосной обыкновенной, лиственницей сибирской и пихтой. Гарь А имела площадь 38,647 км². Нарушенность древостоя пожарами была низкой, характерной либо для периферийных участков затухающих интенсивных пожаров, либо для гарей, пройденных низовыми пожарами. Гарь Б по площади была примерно в два раза больше и отличалась менее сильными повреждениями леса огнем. Однако на обеих гарях имеются участки со средней степенью повреждения.

Таблица 3. Характеристика гарей тестового участка

Table 3. Characteristics of the burnt forest area of the

\begin{tabular}{|c|c|c|c|c|}
\hline $\begin{array}{c}\text { Название } \\
\text { гари } \\
\text { Name of the } \\
\text { burnt forest } \\
\text { area }\end{array}$ & $\begin{array}{c}\text { Год } \\
\text { образо- } \\
\text { вания } \\
\text { Year of } \\
\text { formation }\end{array}$ & $\begin{array}{c}\text { Площадь, } \\
\text { км }^{2} \\
\text { Area, } \mathrm{km}^{2}\end{array}$ & $\begin{array}{c}\text { Среднее } \\
\text { значение } \\
\text { dNBR } \\
\text { Average } \\
\text { dNBR value }\end{array}$ & $\begin{array}{c}\text { Степень } \\
\text { повреждения } \\
\text { огнем } \\
\text { Degree of fire } \\
\text { damage }\end{array}$ \\
\hline $\mathrm{A}$ & \multirow{2}{*}{1999} & 38,647 & 0,22 & Низкая \\
\hline Б/B & & 71,521 & 0,08 & Low \\
\hline
\end{tabular}
test area 
На рис. 2 представлены расчетные значения NDVI за 16 лет, полученные по снимкам с близкими датами съемки (03.07.1999, 02.07.2002, 24.06.2008, 20.06.2009 и 21.06.2015 гг.). Обращает на себя внимание синхронность изменений значений NDVI на обеих гарях: рост с 1999 по 2002 гг., снижение с 2002 по 2009 гг. и



1

подъем с 2009 по 2015 гг. Обработка снимков и анализ полученных значений dNBR выявили возникновение повторных пожаров в 2008 и 2009 гг. внутри обеих гарей (рис. 2). Вызванные ими повреждения древостоя отразились в минимальных значениях NDVI выгоревших лесных участков.

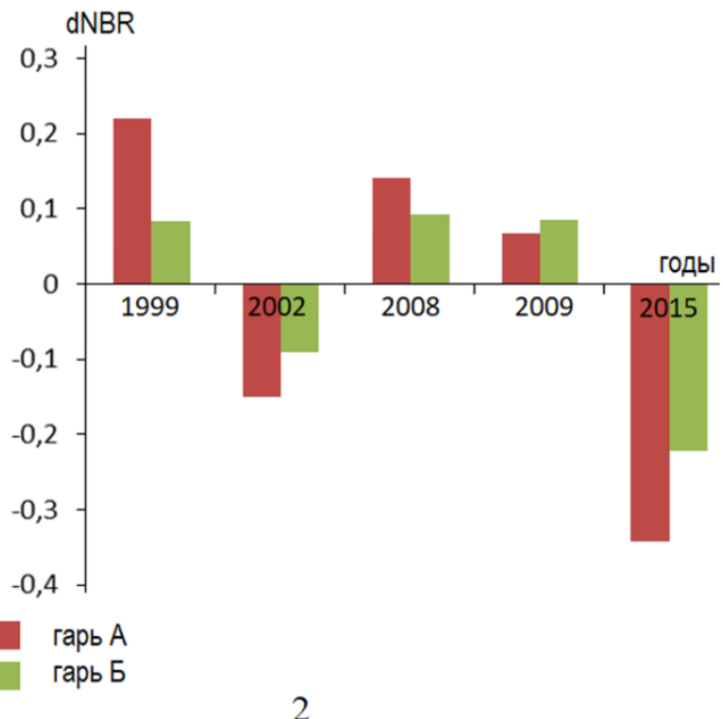

Puc. 2. Графики изменения NDVI (1) и dNBR (2) гарей по годам

Fig. 2. Graphs of changes in NDVI (1) and $d N B R(2)$ of burned-out area by year

В 2006 г. площадь гари А выросла на 1,423 км², на расстоянии 18 км от нее появилась гарь С (рис. 3,1 ). В 2013 г. площадь гари А увеличилась еще на $59,423 \mathrm{kм}^{2}$, гари Б - на 74,11 км². Появилась новая большая гарь Д площадью 245,047 км².

Для подробного анализа динамики восстановления растительного покрова выбрана гарь А, возникшая в
1999 г., поскольку на ней трижды в течение периода с 1999 по 2016 гг. возникали пожары (рис. 3, 2), и на ее территорию имеются снимки за указанный период. Установлено, что значения NDVI распределены по площади гари неравномерно, что говорит о наличии выраженной территориальной изменчивости этого показателя.

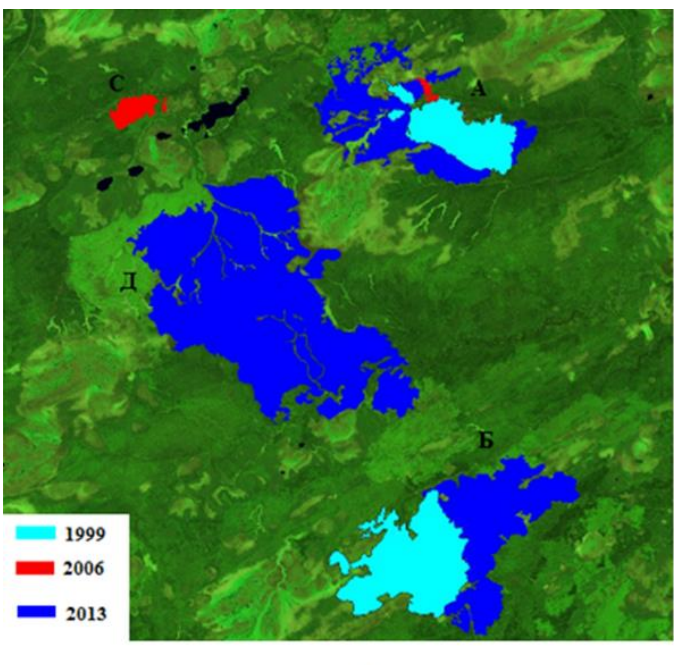

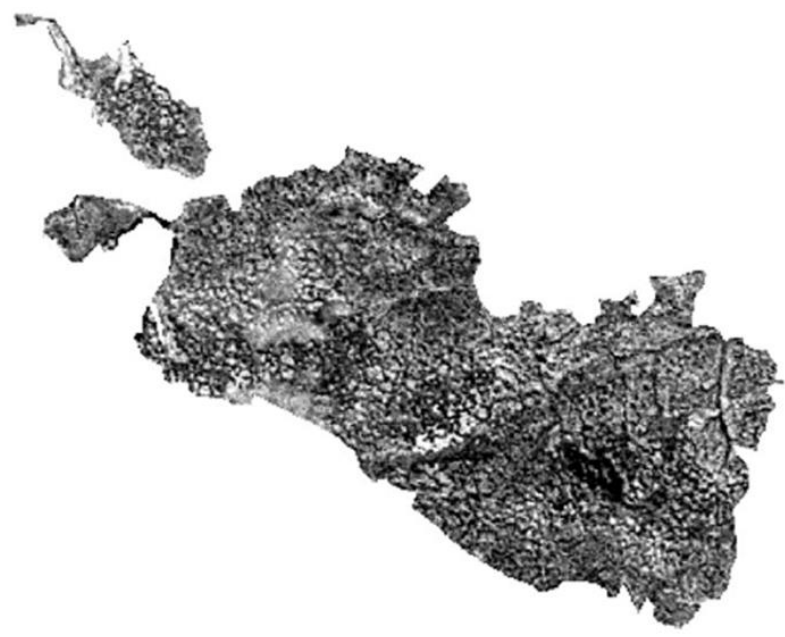

2

Puc. 3. 1 - гари на тестовом участке по годам возникновения (1999, 2006, 2013); 2 - карта NDVI для гари A в 1999 г.

Fig. 3. 1 -burned-out areas in the test area by year of occurrence (1999, 2006, 2013); 2 - NDVI map for burned-out area A in 1999

Имеются явно выраженные устойчивые очаги возгорания на северо-восточной части территории, что свидетельствует о ее предрасположенности к возник- новению лесных пожаров. На юго-западе повреждения менее значительны. Причины локализации лесных пожаров, территориальной изменчивости плотности и со- 
стояния растительности до и после них представляет тему отдельных комплексных исследований. Графики хода средних значений NDVI и NBR приведены на рис. 4. Выявлены аномально резкие перепады показателей гари по сравнению с фоном. Значения NDVI для гарей и тестового участка различаются на 3-56 \%, NBR на 20-198 \%. Различия сохраняются и спустя 17 лет после пожара, что свидетельствует о длительности эколого-динамических процессов восстановления повреждений, нанесенных пожаром лесу.
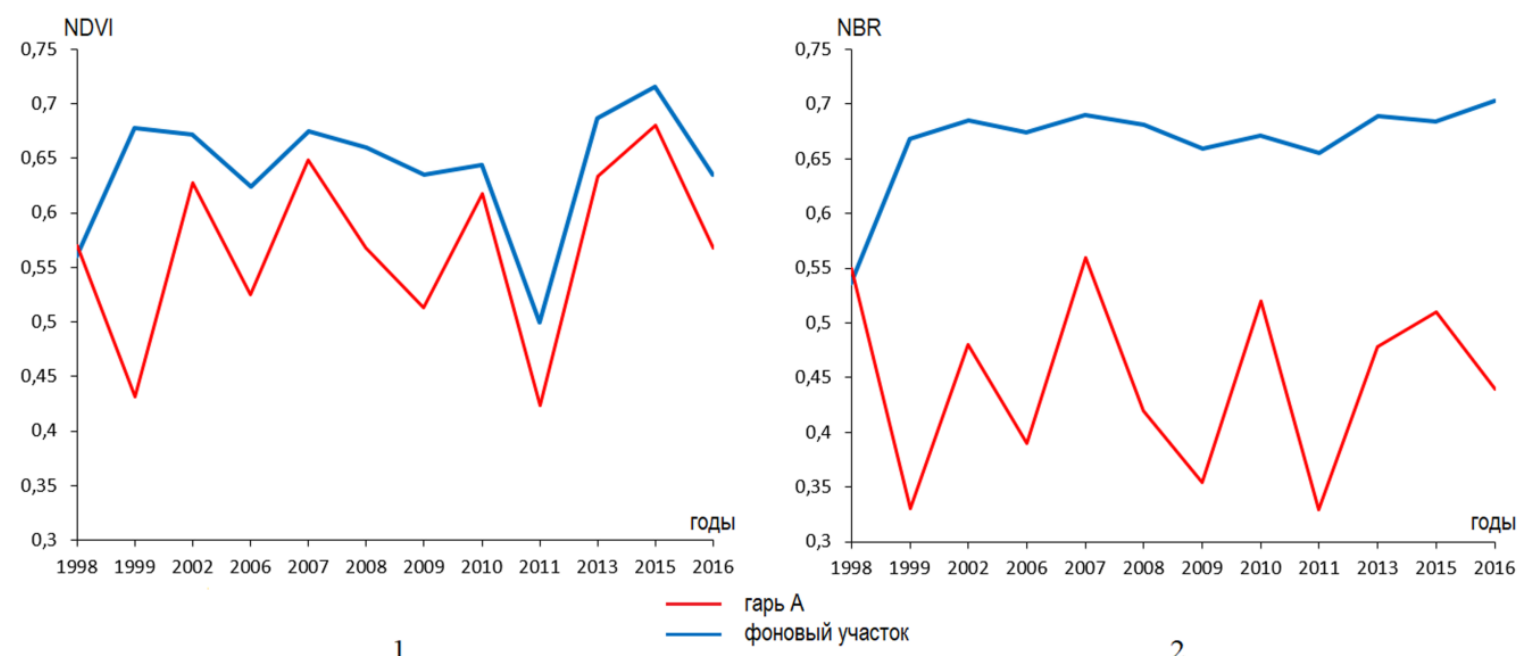

1

Puc. 4. Ход средних значений NDVI (1) и dNBR (2) гари и тестового участка по годам

Fig. 4. Course of the average values of NDVI (1) and $d N B R(2)$ of the burnt forest area and the test area by year

Корреляционный анализа выявил достоверную связь между значениями индексов NBR и NDVI гарей и погодными условиями в пожароопасный сезон (табл. 4) при уровне значимости, равном 0,05.

Таблица 4. Погодные условия и характеристики исследуемых гарей в 1999-2016 г2. [37]

Table 4. Weather conditions and characteristics of the studied burned-out area in 1999-2016 [37]

\begin{tabular}{|c|c|c|c|c|c|c|c|c|c|c|c|c|}
\hline \multirow{4}{*}{$\begin{array}{l}\text { Год } \\
\text { Year }\end{array}$} & \multirow{2}{*}{\multicolumn{4}{|c|}{$\begin{array}{c}\text { Температура } \\
\text { Temperature, }{ }^{\circ} \mathrm{C}\end{array}$}} & \multirow{2}{*}{\multicolumn{4}{|c|}{$\begin{array}{c}\text { Осадки, мм } \\
\text { Precipitation, mm }\end{array}$}} & \multicolumn{2}{|c|}{$\begin{array}{c}\text { Значения NDVI } \\
\text { NDVI Values }\end{array}$} & \multicolumn{2}{|c|}{$\begin{array}{c}\text { Значения NBR } \\
\text { NBR values }\end{array}$} \\
\hline & & & & & & & & & \multicolumn{4}{|c|}{ Гарь/Burned-out area } \\
\hline & Май & Июнь & Июль & Август & Май & Июнь & Июль & Август & $\mathrm{A}$ & 5 & $\mathrm{~A}$ & $\overline{5}$ \\
\hline & May & June & July & August & May & June & July & August & A & $\mathrm{B}$ & A & $\mathrm{B}$ \\
\hline 1999 & 15,0 & 14,2 & 21,4 & 15,3 & 64 & 20 & 36 & 19 & 0,43 & 0,43 & 0,33 & 0,38 \\
\hline 2002 & 12,5 & 16,2 & 17,5 & 15,2 & 88 & 93 & 87 & 43 & 0,63 & 0,60 & 0,48 & 0,47 \\
\hline 2006 & 8,7 & 19,4 & 18,5 & 12,5 & 49 & 122 & 73 & 76 & 0,53 & 0,54 & 0,39 & 0,47 \\
\hline 2007 & 9,6 & 13,8 & 20,5 & 15,0 & 54 & 100 & 85 & 31 & 0,65 & 0,63 & 0,56 & 0,57 \\
\hline 2008 & 10,8 & 16,3 & 19,4 & 15,0 & 79 & 93 & 55 & 31 & 0,57 & 0,59 & 0,42 & 0,48 \\
\hline 2009 & \begin{tabular}{|l|}
9,8 \\
\end{tabular} & 13,2 & 18,6 & 15,7 & 81 & 31 & 60 & 50 & 0,51 & 0,52 & 0,35 & 0,40 \\
\hline 2010 & \begin{tabular}{|l|}
7,2 \\
\end{tabular} & 15,2 & 16,5 & 15,6 & 61 & 104 & 61 & 54 & 0,62 & 0,61 & 0,52 & 0,54 \\
\hline 2011 & 10,4 & 19,4 & 15,5 & 14,0 & 46 & 72 & 45 & 45 & 0,42 & 0,48 & 0,33 & 0,44 \\
\hline 2013 & 6,7 & 14,1 & 19,2 & 16,8 & 32 & 24 & 78 & 67 & 0,63 & 0,64 & 0,48 & 0,53 \\
\hline 2015 & \begin{tabular}{|l|}
11,9 \\
\end{tabular} & 18,4 & 18,9 & 15,9 & 36 & 86 & 63 & 28 & 0,68 & 0,67 & 0,51 & 0,54 \\
\hline 2016 & \begin{tabular}{|l|}
9,1 \\
\end{tabular} & 19,0 & 19,9 & 17,1 & 26 & 95 & 94 & 75 & 0,56 & 0,61 & 0,44 & 0,53 \\
\hline
\end{tabular}

Корреляция между значениями индексов NBR и NDVI гарей и средними значениями температуры воздуха и количества осадков оказалась отрицательной средней и слабой для мая; сильной и средней для июля и слабой для августа. Осадки связаны со значениями индексов NBR и NDVI гарей со средней силой: в мае и июне отрицательно, в августе положительно. Это свидетельствует о достаточном увлажнении экотопов в начале вегетационного периода, последующем просыхании почвы, оптимальном для жизнедеятельности деревьев, и ее последующем иссушении, предопределяющем возможность возникновения лесных пожаров.

Полученные результаты можно интерпретировать следующим образом. Отрицательная корреляция про- дуктивности фитоценозов с погодными условиями (температура воздуха и количество атмосферных осадков) свидетельствует о неоптимальности погодных условий в начале вегетационного периода. Дальнейшая стимуляция роста и развития вегетативной сферы индуцируется умеренными осадками и высокими температурами воздуха, что объяснимо изменением направленности метаболизма: в начальный период роста органы вегетативной сферы деревьев активно потребляют питательные вещества, накопленные в древесине [38]; с июля они сами становятся донорами ассимилятов. Жаркие и сухие условия июля ведут к постепенному снижению влажности почвы судя по значениям NDVI, они оптимальны в начале и субоптимальны в конце месяца. Иссушение почвы 
сопровождается снижением значений NDVI. Происходит возгорание древостоя, регистрируемое по росту значений NBR гарей.

\section{Заключение}

В ходе исследования с помощью дистанционного зондирования Земли из космоса и геоинформационных технологий проведен сравнительный анализ динамики пост-пирогенного изменения состояния растительного покрова тестового участка. Выявлены резкие перепады значений NDVI и NBR гари по сравнению с тестовым участком. Аномальный ход их динамики обусловлен пройденными пожарами, причем достоверная разница между средними значениями индекса NBR гари и тестового участка является значительной спустя 17 лет после пожара, что свидетельствует о длительности эколого-динамических процессов восстановления повреждений, нанесенных пожаром лесу. По данным корреляционного анализа установлены закономерности зависимости значений NDVI и NBR от погодных условий. C их помощью выявлены особенности развития деревьев в разных гидротермических условиях и предрасположенность экотопов к возникновению пожаров и образованию гарей. Показана достоверная связь между изученными параметрами участков и средними значениями температуры воздуха и количества осадков в разные

\section{СПИСОК ЛИТЕРАТУРЬ}

1. Hirschberger P. Forests ablaze. Causes and effects of global forest fires. - Deutschland, Berlin: WWF, 2017. - 108 p. URL: https://www.wwf.de/fileadmin/fm-wwf/Publikationen-PDF/WWFStudy-Forests-Ablaze.pdf (дата обращения 15.03.2021).

2. US Forest Service. URL: https://www.fs.fed.us (дата обращения 15.03.2021).

3. Green Policy. URL: http://www.greenpolicy360.net (дата обращения 15.03.2021)

4. Berry L.E., Arsenault A. Regional case studies. the ecological importance of mixed-severity fires. - 2015. URL: https://www. sciencedirect.com/book/9780128027493/the-ecological-

importance-of-mixed-severity-fires (дата обращения 15.03.2021).

5. Giglio L., Randerson J.T., Van der Werf G.R. Analysis of daily, monthly and annual burned area using the fourth-generation global fire emissions database (GFED4) // Journal of Geophysica Research. - 2013. - V. 118. - P. 1-12. DOI: 10.1002/jgrg.20042.

6. Göltenboth F., Langenberger G., Widmann P. Tropical lowland evergreen rainforest // Ecology of Insular Southeast Asia. 2006. - P. 297-383. URL: https://www.sciencedirect.com/science/ article/pii/B9780444527394500176 (дата обращения 15.03.2021)

7. Пасько О.А., Захарченко А.В., Ковязин В.Ф. Анализ землеустройства лесного фонда // Известия Томского политехнического университета. Инжиниринг георесурсов. - 2021. T. 332. - № 2. - C. 127-138.

8. Baranovskii N.V., Kirienko V.A. Ignition of forest combustible materials in a high-temperature medium // Journal of Engineering Physics and Thermophysics. - 2020. - V. 93 (5). - P. 1266-1271. DOI: 10.1007/s10891-020-02230-4.

9. Korovin G.N., Isaev A.S. Forest fire protection as the most important element of national security of Russia // Forest Bulletin. - 1998. P. 8-9. URL: https://ec.europa.eu/echo/what-we-do/civil-protection/ forest-fires_en (дата обращения 15.03.2021).

10. Kovyazin V., Romanchikov A., Pasko O. Comparative analysis of forest lands cadastral appraisal estimated with regards to wood and food resources // IOP Conference Series: Earth and Environmental Science. - 2015. - V. 27 (1). DOI: 10.1088/17551315/27/1/012039.

11. Оценка состояния припоселковых кедровников Томской области с использованием данных дистанционного зондирова- месяцы пожароопасного периода. Она является отрицательной средней и слабой силы для мая; сильной и средней для июля и слабой для августа. Осадки связаны со значениями индексов NBR и NDVI гарей со средней силой: в мае и июне отрицательно, в августе положительно.

Следует отметить, что лесные пожары являются естественным природным процессом, а для некоторых типов леса, к примеру кедровых, необходимым звеном сукцессионного цикла. Их отсутствие ведет к снижению качества лесных ресурсов, накоплению горючих материалов и провоцирует обширные неконтролируемые пожары. Особенностью современного периода является нарушение природной ритмики пожаров потеплением, хозяйственной деятельностью человека, инвазией разного вида вредителей леса и т. д. Представленные в исследовании ряды наблюдения, несомненно, коротки и не охватывает сукцессионного цикла в 100 и более лет. Вместе с тем они позволяют выявить определенные закономерности пост-пирогенной динамики лесов для анализа скорости и направленности этих процессов, а также использования в практической деятельности.

Работа выполнена в Томском политехническом университете в рамках программы повышения конкурентоспособности Томского политехнического университета.

ния Земли / О.А. Пасько, О.С. Токарева, А.Д.А. Алшаиби, Т.Ю. Черникова, П. Кабраль // Известия Томского политехнического университета. Инжиниринг георесурсов. - 2019. T. 330. - № 1. - С. 98-109.

12. Лесной комплекс Томской области. URL: http://tomsk.gov.ru/ ru/ekonomika/lesnoy-kompleks (дата обращения 15.03.2021).

13. Экологический мониторинг: Состояние окружающей среды Томской области в 2008 году / А.М. Адам, В.А. Коняшкин, С.Н. Воробьев, Н.В. Горина. - Томск: Изд-во «Оптимум», $2009-144 \mathrm{c}$.

14. Spatial organization of forestfund / O.A. Pasko, V.F. Kovyazin, A.V. Zakharchenko, N.A. Lebedeva // IOP Conference Series: Earth and Environmental Science. - 2020. DOI: https:// iopscience.iop. org/article/10.1088/1755-1315/574/1/012061

15. Оценка динамики и нарушенности лесного покрова в Среднем Поволжье по снимкам Landsat / О.Н. Воробьев, Э.А. Курбанов, Ю.А. Полевщикова, С.А. Лежнин // Современные проблемы дистанционного зондирования Земли из космоса. - 2016. T. 13. - № 4. - C. 124-134.

16. The Worldwide Reference System. URL: https://landsat.gsfc.nasa. gov/about/worldwide-reference-system (дата обращения 15.03.2021).

17. Aboveground biomass prediction by Sentinel1 multitemporal data in central Italy with integration of ALOS2 and Sentinel 2 data / G.V. Laurin, J. Balling, P. Corona, W. Mattioli, D. Papale, N. Puletti, M. Rizzo, J. Truckenbrodt, M. Urban // Journal of Applied Remote Sensing. - 2018. - V. 12 (1). - 016008. URL: http://dx.doi.org/10.1117/1.JRS.12.016008 (дата обращения 15.03.2021).

18. Катаев М.Ю., Кислов А.В., Самохин Е.А. Оценка состояния хвойных растений методами компьютерного зрения // Доклады Томского государственного университета систем управления и радиоэлектроники. -2020 . - Т. 23. - № 1. - С. 70-75.

19. Remote sensing estimates of stand-replacement fires in Russia, 2002-2011 / A. Krylov, J.L. Mc Carty, P. Potapov, T. Loboda, A. Tyukavina, S. Turubanova, M. Hansen // Env. Res. Lett. 2014. - V. 9 (10). - P. 1-8. URL: http://dx.doi.org/10.1088/17489326/9/10/105007 (дата обращения 15.03.2021).

20. Барталев С.А., Стыценко Ф.В., Егоров В.А. Спутниковая оценка гибели лесов России от пожаров // Лесоведение.2015. - № 2. - C. 83-94. 
21. Оценка точности и сопоставимости тематических карт лесного покрова разного пространственного разрешения на примеpe Среднего Поволжья / Э.А. Курбанов, О.Н. Воробьев, А.В. Губаев, С.А. Лежнин, Ю.А. Полевщикова // Современные проблемы дистанционного зондирования Земли из космоса. 2016. - T. 13. - № 1. - С. 36-48.

22. Экспресс-картографирование повреждений лесов России пожарами по спутниковым данным Landsat / C.A. Барталев, Е.А. Лупян, Ф.В. Стыценко, О.Ю. Панова, В.Ю. Ефремов // Современные проблемы дистанционного зондирования Земли из космоса. - 2014. - Т. 11. - № 1. - С. 9-20.

23. Использование данных дистанционного зондирования в задачах лесной отрасли / В.А. Хамедов, В.Н. Копылов, Ю.М. Полищук, С.В. Шимов // Современные проблемы дистанционного зондирования Земли из космоса. - 2006. - Т. 11. - № 4. C. $217-229$.

24. Epting J., Verbyla D. Landscape-level interactions of prefire vegetation, burn severity, and postfire vegetation over a 16-year period in interior Alaska // Canadian journal of forest research. 2005. - V. 35. - P. 1367-1377. URL: http://dx.doi.org/10.1139/ х05-060 (дата обращения 15.03.2021).

25. Щербов Б.Л., Лазарева Е.В., Журкова И.С. Лесные пожары и их последствия. - Новосибирск: Изд-во СО РАН, филиал «ЕО», 2015. - $154 \mathrm{c}$.

26. Kovalyov A.V., Tokareva O.S. Using MODIS NDVI products for vegetation state monitoring on the oil production territory in Western Siberia // MATEC Web of Conferences. - Les Ulis: Space Engineering, 2016. - V. 48. URL: http://dx.doi.org/ 10.1051/matecconf/20164805003 (дата обращения 15.03.2021).

27. Wotton B.M., Flannigan M.D., Marshall G.A. Potential climate change impacts on fire intensity and key wildfire suppression thresholds in Canada // Environmental Research Letters. - 2017. V. 12 (9). URL: http://iopscience.iop.org/1748-9326/12/9/095003 (дата обращения 15.03.2021).

28. Flannigan M.D., Cantin A.S Climate change impacts on future boreal fire regimes // Forest Ecology and Management. - 2012. V. 294. - P. 35-44. DOI: 10.1016/j.foreco.2012.09.027.

29. Wildfire management in Canada: review, challenges and opportunities / C. Tymstra, B. Stocks, X. Cai, M.D. Flannigana // Progress in
Disaster Science. - 2020. - V.5. URL: https://www. sciencedirect.com/science/article/pii/S2590061719300456 (дата обращения 15.03.2021).

30. Projected increase in lightning strikes in the United States due to global warming / D. Romps, J. Seeley, D. Vollaro, J. Molinari // Science. - 2014. - V.346 (6211). - P. 851-854. DOI: $10.1126 /$ science. 1259100

31. Monitoring vegetation systems in the great plains with ERTS / J.W. Rouse, R.H. Haas, J.A. Scheel, D.W. Deering // 3rd Earth Resource Technology Satellite (ERTS) Symposium. - USA, Washington, 10-14 December 1974. - V. 1. - P. 309-317.

32. Hudak A.T., Morgan P., Bobbitt M.J. The relationship of multispectral satellite imagery to immediate fire effects // Fire Ecology Special Issue. - 2007. - V. 3 (1). - P. 64-90. URL: https://fireecology.springeropen.com/articles/10.4996/fireecology. 0301064 (дата обращения 15.03.2021)

33. Landsat Missions. Documents. URL: https://www.usgs.gov/corescience-systems/nli/landsat/files (дата обращения 15.03.2021)

34. Handbook for detecting land cover changes with Landsat data archive. URL: https://docplayer.net/20015286-Handbook-fordetecting-land-cover-changes-with-landsat-data-archive.html (дата обращения 15.03.2021).

35. Коррекция материалов Landsat. URL: http:/gis-lab.info/qa/ landsat-data-correction.html (дата обращения 15.03.2021).

36. Мониторинг природных пожаров со спутников. URL: http://fires.ru (дата обращения 15.03.2021).

37. Архив погоды в Томске. URL: https://rp5.ru/\%D0\%90\%D1\%80\% D1\%85\%D0\%B8\%D0\%B2 \%D0\%BF\%D0\%BE\%D0\%B3\%D0\% BE\%D0\%B4\%D1\%8B_\%D0\%B2_\%D0\%A2\%D0\%BE\%D0\%B $\mathrm{C} \% \mathrm{D} 1 \% 81 \% \mathrm{D} 0 \% \mathrm{BA} \% \mathrm{D} 0 \% \mathrm{~B} 5$ (дата обращения: 15.03 .2021 ).

38. Велисевич С.Н., Хуторной О.В. Влияние климатических факторов на радиальный рост кедра и лиственницы в экотопах с различной влажностью почвы на юге Западной Сибири // Journal of Siberian Federal University. Biology. - 2009. - V. 1 (2). P. 117-132. URL: http://elib.sfu-kras.ru/handle/2311/1220 (дата обращения: 15.03.2021).

Поступила: 09.04.2021 2.

\section{Информация об авторах}

Tокарева O.C., кандидат технических наук, доцент отделения информационных технологий Национального исследовательского Томского политехнического университета.

Алиаиби А.Д.А., ведущий сотрудник Главного управление образования Диялы.

Пасько О.A., доктор сельскохозяйственных наук, кандидат биологических наук, заведующий сектором экспериментальных исследований Агрофизического научно-исследовательского института. 
UDC 630:628.8:911.5/.9

\title{
ASSESSMENT OF RESTORATION DYNAMICS OF BURNT FOREST AREA VEGETATION USING LANDSAT SATELLITE DATA
}

\author{
Olga S. Tokareva1, \\ ost@tpu.ru
}

\author{
Ahmet D.A. Alshaibi², \\ ahmedalshaiby88@gmail.com \\ Olga A. Pasko3, \\ oap@tpu.ru \\ 1 National Research Tomsk Polytechnic University, \\ 30, Lenin avenue, Tomsk, 634050, Russia. \\ 2 General Department of Education, Diyala, \\ 1, Almuhafada avenue, Baquba, 32001, Iraq. \\ ${ }^{3}$ Agrophysical Research Institute, \\ 14, Grazhdansky avenue, St-Petersburg, 195220, Russia.
}

Relevance. Up to 400 thousand forest fires that occur annually on Earth lead to the release of up to four billion tons of carbon into the atmosphere and the burning of up to $0,5 \%$ of the forest area. Forest fires destroy wood resources, reduce the efficiency of their use, and cause enormous damage to the economy. Operational and objective information about their consequences is in demand for solving a set of theoretical and practical problems in the field of land management, cadastre and monitoring of forest lands, as well as for scientific justification of the use, restoration, conservation and protection of forests.

Object: forest lands that exposed to fires.

Subject: post-pyrogenic dynamics of vegetation cover on the example of forest harems of the Tomsk region.

Methods: thematic mapping of the territory according to the state of vegetation; estimation of the amount of photosynthetically active biomass NDVI (Normalize Difference Vegetation Index) and normalized burn index NBR (Normalized Burn Ratio) according to remote sensing data; use of satellite images from the archive of the US Geological Survey and the Internet service Earth Explorer 1999-2017; analysis of information from Landsat satellites 5 (camera TM), 7 (ETM+) and 8 (OLI) using geoinformation technologies and statistical processing of the received data.

Results. The authors have assessed the vegetation state of the burnt forest areas in comparison with the background forest area of similar breed composition (46\% - Siberian Pine, $36 \%$ - Hanging birch, $11 \%$ - Common Aspen, $7 \%$ - Common Pine and Siberian Larch). The disturbance of the vegetation of the studied burnt forest areas is characterized as low. The study uses Landsat satellite images acquired in the period from 1998 to 2016 and obtained from the archives of the US Geological Survey. The NDVI and NBR were calculated for the burnt forest areas and background areas. Sharp differences in their values and anomalous course of annual dynamics for burnt forest area are revealed. The NDVI values for the burnt forest areas and the background area differed by 3-56 \%, and the NBR values by 20-198\%. The differences persisted 17 years after the fire. The correlation analysis revealed a significant relationship between the values of the NBR and NDVI of the burnt forest areas and the average values of air temperature and precipitation in the fire season. It turned out to be negative medium and weak strength for May; strong and medium for July and weak for August. Precipitation is associated with the values of the NBR and NDVI of the burnt forest areas with an average strength: negative in May and June, positive in August. This indicates sufficient moisture of the ecotopes at the beginning of the growing season, subsequent drying of the soil, optimal for the vital activity of trees, and its desiccation, which determines the possibility of forest fires. There is a clear territorial variability of the NDVI and NBR values within the burnt forest area boundaries.

Key words:

$N D V I$, burnt forest area, vegetation cover, remote sensing, NBR, forest fire.

The research was carried out at Tomsk Polytechnic University within the framework of Tomsk Polytechnic University Competitiveness Enhancement Program.

\section{REFERENCES}

1. Hirschberger P. Forests ablaze. Causes and effects of global forest fires. Deutschland, Berlin, WWF, 2017. 108 p. Available at: https://www.wwf.de/fileadmin/fm-wwf/Publikationen-PDF/WWFStudy-Forests-Ablaze.pdf (accessed 15 March 2021).

2. US Forest Service. Available at: https://www.fs.fed.us (accessed 15 March 2021).

3. Green Policy. Available at: http://www.greenpolicy360.net (accessed 15 March 2021).

4. Berry L.E., Arsenault A. Regional case studies. The Ecological Importance of Mixed-Severity Fires, 2015. Available at: https://www.sciencedirect.com/book/9780128027493/the- ecological-importance-of-mixed-severity-fires (accessed 15 March 2021).

5. Giglio L., Randerson J.T., Van der Werf G.R. Analysis of daily, monthly, and annual burned area using the fourth-generation global fire emissions database (GFED4). Journal of Geophysical Research, 2013, vol. 118, pp. 1-12. DOI: 10.1002/jgrg.20042.

6. Göltenboth F., Widmann P. Tropical lowland evergreen rainforest. Ecology of Insular Southeast Asia, 2006. Available at: https://www.sciencedirect.com/science/article/pii/B978044452739 4500176 (accessed 15 March 2021).

7. Pasko O.A., Zakharchenko A.V., Kovyazin V.F. Analysis of land management of the forest fund. Bulletin of the Tomsk Polytechnic 
University. Geo Assets Engineering, 2021, vol. 332, no 2, pp. 127-138. In Rus.

8. Baranovskii N.V., Kirienko V.A. Ignition of forest combustible materials in a high-temperature medium. Journal of Engineering Physics and Thermophysics, 2020, vol. 93 (5), pp. 1266-1271. DOI: $10.1007 / \mathrm{s} 10891-020-02230-4$.

9. Korovin G.N., Isaev A.S. Forest fire protection as the most important element of national security of Russia. Forest Bulletin, 1998, pp. 8-9. Available at: https://ec.europa.eu/echo/what-wedo/civil-protection/forest-fires_en (accessed 15 March 2021).

10. Kovyazin V., Romanchikov A., Pasko O. Comparative analysis of forest lands cadastral appraisal estimated with regards to wood and food resources. IOP Conference Series: Earth and Environmental Science, 2015, vol. 27 (1). DOI: 10.1088/1755-1315/27/1/012039.

11. Pasko O.A., Tokareva O. S., Alshaibi A.D.A., Chernikova T.Yu., Kabral P. Assessment of the state of near-village cedar forests of the Tomsk region using remote sensing data. Bulletin of the Tomsk Polytechnic University. Geo Assets Engineering, 2019, vol. 330, no. 1, pp. 98-109. In Rus.

12. Lesnoy kompleks Tomskoy oblasti [Forest complex of Tomsk region]. Available at: http://tomsk.gov.ru/ru/ekonomika/lesnoykompleks (accessed 15 March 2021)

13. Adam A.M., Konyashkin V.A., Vorobyov S.N., Gorina N.V. Ekologicheskiy monitoring: sostoyanie okruzhayuschey sredi Tomskoy oblasti v 2008 godu [Ecological monitoring: the state of the environment of the Tomsk region in 2008]. Tomsk, Optimum Publ. house, 2009. $144 \mathrm{p}$.

14. Pasko O.A., Kovyazin V.F., Zakharchenko A.V., Lebedeva N.A. Spatial organization of forestfund. IOP Conference Series: Earth and Environmental Science, 2020. DOI: https://iopscience.iop. org/article/10.1088/1755-1315/574/1/012061.

15. Vorobev O.N., Kurbanov E.A., Polevshchikova Yu.A., Lezhnin S.A. Evaluation of the dynamics and disturbance of forest cover in the Middle Volga region based on Landsat images. Current problems in remote sensing of the Earth from space, 2015, vol. 12 no. 5, pp. 203-221. In Rus.

16. The Worldwide Reference System. Available at: https:/landsat gsfc.nasa.gov/about/worldwide-reference-system (accessed 15 March 2021).

17. Laurin G.V., Balling J., Corona P., Mattioli W., Papale D., Puletti N., Rizzo M., Truckenbrodt J., M. Urban Aboveground biomass prediction by Sentinel1 multitemporal data in central Italy with integration of ALOS2 and Sentinel 2 data. Journal of Applied Remote Sensing, 2018, vol. 12, no. 1, 016008. Available at: http://dx.doi.org/10.1117/1.JRS.12.016008 (accessed 15 March 2021).

18. Kataev M.Yu., Kislov A.V., Samokhin E.A. Assessment of the state of coniferous plants by computer vision methods. Reports of the Tomsk State University of Control Systems and Radioelectronics, 2020, vol. 23, no. 1, pp. 70-75. In Rus.

19. Krylov A., Mc Carty J. L., Potapov P., Loboda T., Tyukavina A., Turubanova S., Hansen M. Remote sensing estimates of standreplacement fires in Russia, 2002-2011. Journal of Applied Remote Sensing, 2014, vol. 9 (10), pp. 1-8. Available at: http:// dx.doi.org/10.1088/1748-9326/9/10/105007 (accessed 15 March 2021)

20. Bartalev S.A., Stytsenko F.V., Egorov V.A. Satellite assessment of the death of Russian forests from fires. Forest Science, 2015, no. 2 , pp. 83-94. In Rus.

21. Kurbanov E.A., Vorobyev O.N., Gubaev A.V., Lezhnin S.A., Polevshchikova Yu.A. Assessment of the accuracy and comparability of thematic maps of forest cover of different spatial resolution on the example of the Middle Volga region. Current problems in remote sensing of the Earth from space, 2016, vol. 13. no. 1, pp. 36-48. In Rus.
22. Bartalev S.A., Lupyan E.A., Stytsenko F.V., Panova O.Yu., Efremov V.Yu. Express mapping of forest damage in Russia by fires from satellite images. Current problems in remote sensing of the Earth from space, 2014, vol. 11, no. 1, pp. 9-20. In Rus.

23. Khamedov V.A., Kopylov V.N., Polishchuk Yu.M., Shimov S.V. The use of remote sensing data in the problems of the forest industry. Current problems in remote sensing of the Earth from space, 2006, vol. 11, no. 4, pp. 217-229.

24. Epting J., Verbyla D. Landscape-level interactions of prefire vegetation, burn severity, and postfire vegetation over a 16 -year period in interior Alaska. Canadian journal of forest research, 2005, vol. 35, pp. 1367-1377.

25. Shcherbov B.L., Lazareva E.V., Zhurkova I.S. Lesnye pozhary $i$ $i k h$ posledstviya [Forest fires and their consequences]. Novosibirsk, SO RAN Publ., branch GEO, 2015. 154 p.

26. Kovalyov A.V., Tokareva O.S. Using MODIS NDVI products for vegetation state monitoring on the oil production territory in Western Siberia. MATEC Web of Conferences. Les Ulis: Space Engineering, 2016, vol. 48. Available at: http://dx.doi.org/10.1051/ matecconf/20164805003 (accessed 15 March 2021).

27. Wotton B.M., Flannigan M.D., Marshall G.A. Potential climate change impacts on fire intensity and key wildfire suppression thresholds in Canada. Environmental Research Letters, 2017, vol. 12 (9). Available at: http://iopscience.iop.org/1748-9326/ 12/9/095003 (accessed 15 March 2021).

28. Flannigan M.D., Cantin A.S. Climate change impacts on future boreal fire regimes. Forest Ecology and Management, 2012, vol. 294 pp. 35-44. DOI:10.1016/j.foreco.2012.09.027.

29. Tymstra C., Stocks B., Cai X., Flannigana M.D. Wildfire management in Canada: review, challenges and opportunities. Progress in Disaster Science, 2020, vol. 5. Available at: https://www.sciencedirect.com/science/article/pii/S259006171930 0456 (accessed 15 March 2021).

30. Rouse J.W., Haas R.H., Scheel J.A., Deering D.W. Monitoring vegetation systems in the great plains with ERTS. 3rd Earth Resource Technology Satellite (ERTS) Symposium. USA, Washington, 10-14 December, 1974. Vol. 1, pp. 309-317.

31. Romps D., Seeley J., Vollaro D., Molinari J. Projected increase in lightning strikes in the United States due to global warming. Science, 2014, vol. 346 (6211), pp. 851-854. DOI: 10.1126/science. 1259100

32. Hudak A.T., Morgan P., Bobbitt M.J. The relationship of multispectral satellite imagery to immediate fire effects. Fire Ecology Special Issue, 2007, vol. 3 (1), pp. 64-90.

33. Landsat Missions. Documents. Available at: https://www.usgs. gov/core-science-systems/nli/landsat/files (accessed 15 March 2021).

34. Handbook for detecting land cover changes with Landsat data archive. Available at: (accessed 15 March 2021).

35. Korrektaiya materialov Landsat [Correction of Landsat materials.]. Available at: http://gis-lab.info/qa/landsat-data-correction.html (accessed 15 March 2021).

36. Monitoring prirodnykh pozharov so sputnikov [Monitoring of wildfires from satellites]. Available at: http://fires.ru (accessed 15 March 2021).

37. Arhhiv pogody [Weather archive]. Available at: https://rp5.ru/\%D0\% 90\%D1\%80\%D1\%85\%D0\%B8\%D0\%B2_\%D0\%BF\%D0\%BE\% D0\%B3\%D0\%BE\%D0\%B4\%D1\%8B \%D0\%B2 \%D0\%A2\%D0 \%BE\%D0\%BC\%D1\%81\%D0\%BA\%D0\%B5 (accessed 15 March 2021).

38. Velisevich S.N., Khutornoy O.V. Influence of climatic factors on the radial growth of cedar and larch in ecotopes with different soil moisture in the south of Western Siberia. Journal of Siberian Federal University. Biology, 2009, vol. 1 (2), pp. 117-132. In Rus.

Received: 9 April 2021.

Information about the authors

Olga S. Tokareva, Cand. Sc., associate professor, National Research Tomsk Polytechnic University.

Ahmet D.A. Alshaibi, leading employee, General Department of Education, Diyala.

Olga A. Pasko, Dr. Sc., Cand. Sc., head of the experimental research sector, Agrophysical Research Institute. 